\title{
Laparoscopic Resection of Duodenal Giant Brunner's Gland Hamartoma
}

\author{
Sergio Carandina, MD, Perrine Mathonet, MD, Guy Bernard Cadière, MD, PhD \\ Department of Digestive and Metabolic Surgery, Jean Verdier Hospital, Paris XIII University-University Hospitals of Paris \\ Seine Saint-Denis, Paris, France (Dr. Carandina). \\ Department of Gastrointestinal Surgery, European School of Laparoscopic Surgery, Saint-Pierre University Hospital, \\ Brussels, Belgium (Drs. Mathonet, Cadière).
}

\begin{abstract}
Background: Brunner's gland hamartoma (BGH) is a rare, proliferative entity arising from alkaline-secreting glands located mainly in the duodenum. In most cases, BGH develops as a polypoid pedunculated lesion of 1 to $2 \mathrm{~cm}$ in diameter, whereas in a few cases, the so-called "giant BGH" can reach $12 \mathrm{~cm}$ in size. Removal of BGH is required in symptomatic patients, and treatment options include the endoscopic or surgical approach.
\end{abstract}

Case Report: We report the case of a 33-year-old woman affected by a symptomatic giant BGH. Laparoscopic local surgery was planned. With the patient under general anesthesia, a laparoscopic Kocher maneuver and a polypectomy via duodenectomy were performed. Then the duodenotomy was closed with a horizontal manual suture. The operative time was 75 minutes and blood loss was $40 \mathrm{~mL}$.

Results: The patient made an uneventful recovery and is well at a one-year follow-up. Pathologic examination results showed a $10 \times 2.5-\mathrm{cm}$ BGH without signs of malignancy or dysplasia.

Conclusion: Laparoscopic transduodenal resection can be considered a safe and feasible procedure for large polyps that are not candidates for endoscopic resection.

Key Words: Brunner's gland hamartoma, Duodenal polyp, Laparoscopy, Excision.

Citation Carandina S, Mathonet P, Cadière GB. Laparoscopic resection of duodenal giant brunner's gland hamartoma. CRSLS e2014.00163. DOI 10.4293/CRSLS.2014.00163.

Copyright (C) 2014 SLS This is an open-access article distributed under the terms of the Creative Commons Attribution-Noncommercial-ShareAlike 3.0 Unported license, which permits unrestricted noncommercial use, distribution, and reproduction in any medium, provided the original author and source are credited.

Address correspondence to: Sergio Carandina, Avenue du 14 Juillet, 93140 Bondy, Paris, France. Telephone: (+33) 677 593 954, E-mail address: sergio.carandina@ jvr.aphp.fr

\section{INTRODUCTION}

Brunner's glands, described by the anatomist Brunner in 1688, are submucosal mucin-secreting glands. They secrete an alkaline fluid that protects the duodenal epithelium from the acid chyme of the stomach and an enteric hormone inhibiting gastric acid secretion, called enterogastrone. ${ }^{1}$ The duodenal bulb has the higher concentration of Brunner's gland with a decreasing prevalence in the second and third portions of the duodenum. ${ }^{2}$

Lesions arising from the Brunner's glands have been variously referred to as adenoma, hamartoma, or Brunner's glands hyperplasia because of their various types of presentation. Although Brunner's glands hyperplasia refers to multiple, small polypoid lesions, the term Brunner's gland adenoma (BGA) or, interchangeably, Brunner's gland hamartoma $(\mathrm{BGH})$, has been attributed to describing a solitary polypoid mass. ${ }^{3}$

BGA and BGH, initially described by Curveilheir in 1835 , are substantially benign tumors that account for as much as $1 \%$ of duodenal polyps. $1,4,5 \mathrm{BGH}$ is an extremely rare tumor with an estimated incidence of $0.008 \%$ in a single series of 215000 autopsies. ${ }^{6}$

From an etiologic and pathogenetic point of view, BGH remains an obscure entity. It has been postulated that BGH's origin is the result of a compensatory growth of the alkaline-secreting Brunner's gland in response to an in- 
creased acid secretion or to a Helicobacter pylori infection. 3,5

Most patients affected by a BGH are asymptomatic, and lesions are discovered incidentally during imaging or endoscopy studies. Surgical indication is considered when BGH evokes symptoms such as bleeding or obstruction. ${ }^{2}$

Many endoscopic procedures have been described for symptomatic BGH, in addition to more invasive surgical procedures.

We report a case of giant duodenal BGH treated by laparoendoscopic transduodenal polypectomy, with a literature review.

\section{CASE REPORT}

A 33-year-old woman was admitted to the hospital for abdominal pain and anemia. She denied weight loss or use of nonsteroidal antiinflammatory drugs and did not report having any gastrointestinal bleeding.

Gastroscopy identified a large pedunculated polyp arising from the posterior duodenal wall at the junction between the first and second portions of the duodenum, with a hard thickening and tubulo-villous aspect at the extremity. Biopsy results revealed villous atrophy without specificity. The computed tomography scan showed a polyp in the duodenal bulb extending into the third duodenum (Figure 1). Endoscopic ultrasonography confirmed that the lesion was confined to the mucosa without evidence of seromuscular invasion or adjacent adenopathies. On the basis of these findings, we proposed a laparoscopic polypectomy to the patient.

\section{Surgical Technique}

The patient was placed in the supine position with legs apart and arms abducted. The surgeon stood between the patient's legs, with the camera assistant to the patient's right and the assistant and scrub nurse to the patient's left. A pneumoperitoneum was created through a Veress needle inserted into the left upper quadrant. Trocars were placed as follows:

- 11-mm trocar just to the left of the midline, approximately $5 \mathrm{~cm}$ above the umbilicus for the 30-degree angled scope optical system,

- 5-mm trocar on the left anterior axillary line $5 \mathrm{~cm}$ distal to the costal margin,

- 5-mm trocar in the left upper quadrant on the midclavicular line between the first and second trocars for the dominant surgeon's hand,

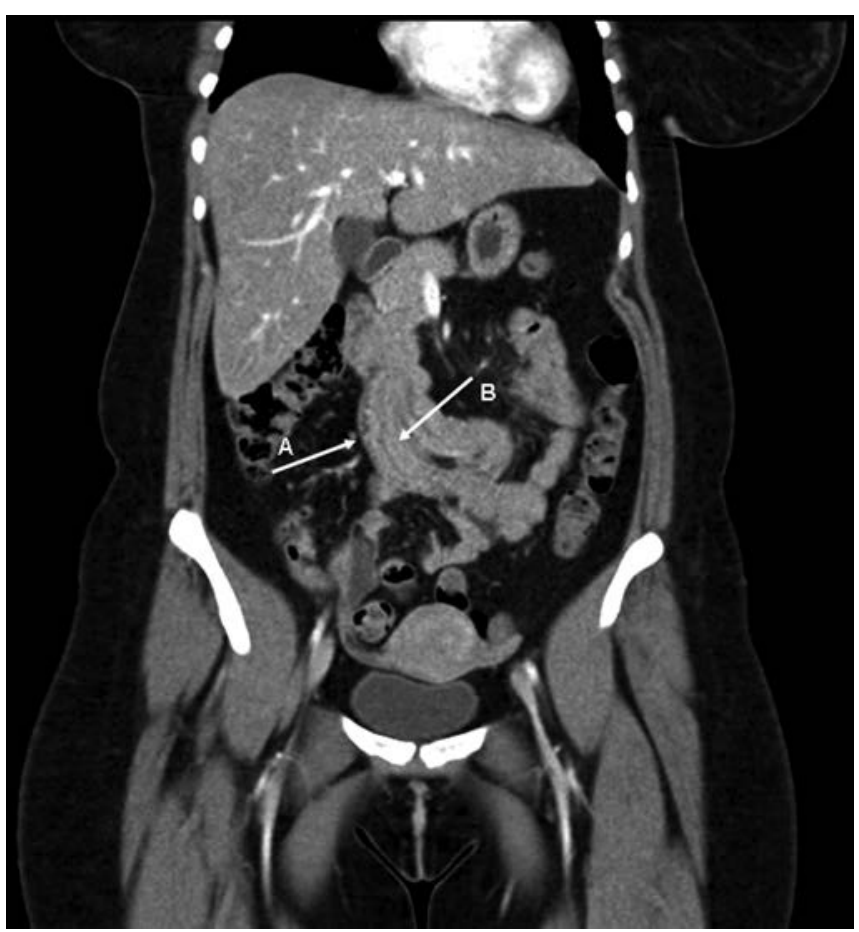

Figure 1. The computed tomography scan showed a large polypoid mass extending from the duodenal bulb to the third portion of the duodenum. A, The arrow points to the duodenal wall. $\mathrm{B}$, The arrow points to the polyp.

- 5-mm trocar in the right upper quadrant on the midclavicular line for the nondominant surgeon's hand, and

- 5-mm trocar used under the xyphoid process for the liver retraction.

Laparoscopic exploration of the abdominal cavity showed a normal serosa of the duodenum and absence of adenopathy or secondary lesions. A Kocher maneuver was performed using a Harmonic scalpel (Ethicon Inc., Somerville, New Jersey). The duodenum was opened longitudinally between the second and third portions. The polyp was exposed through the duodenotomy, dissected, and divided at its base (Figure 2). Then the duodenotomy was closed with a horizontal manual suture technique using 2/0 PDS sutures (Ethicon Inc.). An intraoperative leak test was negative, and the specimen was placed in a plastic bag and retrieved through the 11-mm trocar. After controlled removal of the trocar, this latter was closed in layers. Neither conversion to open surgery nor additional trocars was needed. Operative time was 75 minutes and estimated blood loss was $40 \mathrm{~mL}$.

No postoperative complications occurred. A gastrografin swallow on postoperative day 4 did not show any leaks, 


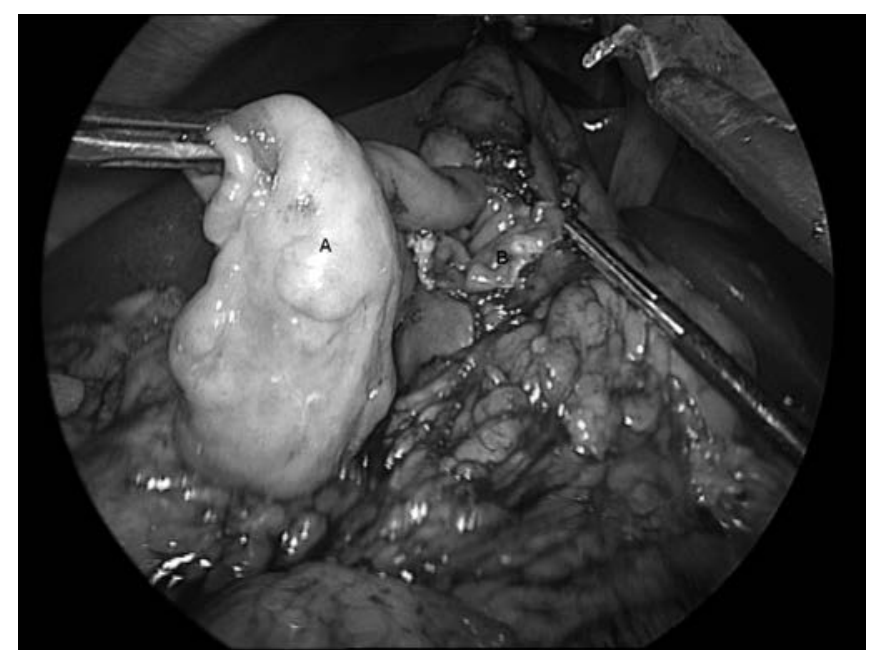

Figure 2. The polyp (A) was exposed trough a 3-cm longitudinal duodenotomy (B).

thus the patient was allowed a liquid diet. The patient was discharged on the fifth postoperative day.

Pathologic examination of the specimen showed a $10 \times$ $2.5-\mathrm{cm} \mathrm{BGH}$. No signs of malignancy or dysplasia were found within the entirety of the polyp.

After 12 months of follow-up, the patient was doing well without any recurrence shown on gastroscopic check-up.

\section{DISCUSSION}

$\mathrm{BGA}$, also known as $\mathrm{BGH}$, is a rare, proliferative entity arising from alkaline-secreting glands located almost exclusively in the submucosal layer of the duodenum. In most cases, BGH develops as a polypoid pedunculated lesion of 1 to $2 \mathrm{~cm}$ in diameter, whereas in a few cases, the so-called "giant BGH" can reach $12 \mathrm{~cm}$ in size. ${ }^{1,2}$

Treatment options include endoscopic excision or surgical resection. Removal of BGH is required in symptomatic patients, but it has also been suggested to prevent the development of complications, especially in the presence of a giant $\mathrm{BGH} .^{3}$

Endoscopic polypectomy represents the ideal approach because it is more cost-effective and less invasive than open surgery. Different endoscopic resection techniques have been described including standard snare polypectomy, injection and polypectomy, injection and cutting, endolooping and polypectomy, and polypectomy with two snares. 7,8 The size of the $\mathrm{BGH}$, the presence of a peduncle, and the expertise of the medical center staff decide the choice of techniqe. Chen et al described the successful removal of a large BGH-6 $\mathrm{cm}$ in length-by applying hemoclips over the stalk's base, the so-called "hemoclip-assisted polypectomy." Endoscopic submucosal dissection, recently introduced for the treatment of duodenal lesions, has also been used by Ohba et al for resection of a large Brunner's gland hyperplasia $(6.5 \times 4 \mathrm{~cm}) .{ }^{9}$ Regardless of the endoscopic technique used, the polyp size is directly proportional to the operative risk of blood loss and duodenal perforation. To our knowledge, no case of endoscopic treatment of such a large polyp has been reported previously in the literature.

When endoscopic interventions fail or are unfeasible because of the high risk of complications in symptomatic patients, surgical resection may be necessary. Surgical options used to treat symptomatic BGH range from local surgical treatment such as duodenotomy with polypectomy to more aggressive and extensive resections, sometimes justified by their ability to mimic duodenal malignancies in presentation.3,10,11 Stewart et al described the case of a broad-based duodenal BGH measuring $10.5 \mathrm{~cm}$ at its major axis, treated with pancreaticoduodenectomy and complicated by a high-output postoperative pancreatic fistula. ${ }^{11}$ Gupta et al instead performed a pancreas-sparing resection via a bilateral subcostal incision for the treatment of an $8 \times 10-\mathrm{cm} \mathrm{BGH}$ arising from the first and second portions of the duodenum, extending beyond the papilla. ${ }^{3}$

In the present case, based on the large size and benign appearance of the lesion, we chose to perform a laparoscopic local surgical resection via duodenectomy. This approach allowed us to completely remove the polyp while preserving vital structures close to the duodenum. This type of operative strategy has already been described for the treatment of several other duodenal lesions. In particular, it has been demonstrated as an effective option for the resection of nonampullary carcinoid tumors smaller than $1 \mathrm{~cm}$ in diameter, and duodenal schwannoma. ${ }^{12,13}$ In all of these reports, the minimally invasive laparoscopic approach has permitted the targeted removal of the lesion with the well-known benefits related to laparoscopy, including a reduction in the postoperative morbidity, length of hospital stay, and, especially in young female patients like ours, an excellent aesthetic result. Scientific literature reports at least two other cases of BGH treated with the laparoscopic approach, but this is the only report concerning the laparoscopic local resection of a duodenal lesion of these dimensions. ${ }^{14,15}$

In conclusion, laparoscopic transduodenal resection can be considered a safe and feasible procedure for large polyps that are not candidates for endoscopic resection. 


\section{References:}

1. Culver EL, Micintyre AS. Sporadic duodenal polyps: classification, investigation, and management. Endoscopy. 2011;43: $144-155$.

2. Levine JA, Burgart LJ, Batts KP, Wang KK. Brunner's gland hamartomas: clinical presentation and pathological features of 27 cases. Am J Gastroenterol. 1995;90:290-294.

3. Gupta V, Singh V, Kalra N, Vaiphei K. Pancreas sparing resection for giant hamartoma of Brunner's glands. J Pancreas. 2009;10:196-199.

4. Terada T. Pathologic observations of the duodenum in 615 consecutive duodenal specimens: I. benign lesions. Int J Clin Exp Pathol. 2012;5:46-51.

5. Rocco A, Borriello P, Compare D, et al. Large Brunner's gland adenoma: case report and literature review. World J Gastroenterol. 2006;112: 1966-1968.

6. Botsford TW, Crowe P, Croker DW. Tumors of the small intestine. A review of experience with 115 cases including a report of a rare case of malignant hemangio-endothelioma. $A m \mathrm{~J}$ Surg. 1962;103:358-365.

7. Matsushita M, Mori S, Uchida K, Okazaki K. Brunner's gland hamartomas: endoscopic submucosal dissection versus snare polypectomy. Dig Dis Sci. 2008;53:594-595.
8. Chen YY, Su WW, Soon MS, Yen HH. Hemoclip-assisted Polypectomy of large duodenal Brunner's gland hamartoma. Dig Dis Sci. 2006;51:1670-1672.

9. Ohba R, Otaka M, Jin M, et al. Large Brunner's gland hyperplasia treated with modified endoscopic submucosal dissection. Dig Dis Sci. 2007;52:170-172.

10. Vyas S, Skipworth JRA, Lytras D, et al. Rare presentation of Brunner's gland adenoma: another differentiation in patients with recurrent "idiopathic" pancreatitis. Hepatobiliary Pancreat Dis Int. 2012;11:107-110.

11. Stewart ZA, Hruban RH, Fishman EF, Wolfgang CL. Surgical management of giant Brunner's gland hamartoma: case report and literature review. World J Surg Oncol. 2009;7:68.

12. Bowers SP, Smith CD. Laparoscopic resection of posterior duodenal bulb carcinoid tumor. Am Surg. 2003;69:792-795.

13. Orsenigo E, Di Paolo S, Staudacher C. Laparoscopic excision of duodenal schwannoma. Surg Endosc. 2007;21:1454-1456.

14. Yi NJ, Kim YW, Han HS, Fleischer GD. Duodenal polypectomy of Brunner's gland hyperplasia using a novel laparoscopic technique. Surg Endosc. 2002;16:1493-1495.

15. Baladas HG, Borody TJ, Smith GS, et al. Laparoscopic excision of a Brunner's gland adenoma of the duodenum. Surg Endosc. 2002;16:1636. 